\title{
Changes in Alcohol-Related Behavior Following an Incident of Traumatic Brain Injury
}

\section{Nimisha Shiwalkar, Danielle Gregor, Rao Fu, Alex Bekker and Jiang-Hong Ye}

Department of Anesthesiology, Pharmacology and Physiology, Rutgers, The State University of New Jersey, New Jersey Medical School, 185 South Orange Avenue, Newark, NJ 07103, USA

"Corresponding author: Jiang-Hong Ye, Department of Anesthesiology, Pharmacology and Physiology, Rutgers, the State University of New Jersey, New Jersey Medical School, 185 South Orange Avenue, Newark, NJ 07103, USA, Tel: + 973-972-1866; Fax: +973-972-4172; E-mail: ye@njms.rutgers.edu

Rec date: August 03, 2017; Acc date: September 05, 2017; Pub date: September 07, 2017

Copyright: (C) 2017 Shiwalkar N, et al. This is an open-access article distributed under the terms of the creative commons attribution license, which permits unrestricted use, distribution, and reproduction in any medium, provided the original author and source are credited.

\begin{abstract}
Pre-existing alcohol related complications are a common occurrence amongst individuals admitted for Traumatic Brain Injury (TBI) and is estimated to be about $44 \%$ to $66 \%$ in TBI patients. In fact, alcohol intoxication is a major cause of TBI. The contribution of alcohol abuse as a cause of TBI and its influence over the pathophysiology of TBI is well studied and well known. However, the influence of TBI on alcohol consumption is still in its preliminary stages. The underlying reasons for it may be the complex interaction between the pathological changes induced by TBI itself and changes in environmental factors following an episode of TBI. The resulting alteration in alcohol-related behaviors post-TBI can affect cognitive and neurological functions and thus can influence the overall recovery of the patient.

Hence, understanding changes in alcohol behavior after TBI, with respect to the timing and causes responsible for the change, is important from the perspective of long-term outcome in these patients. In this review article, we discuss a number of studies to determine changes in alcohol drinking behavior following TBI and summarize the findings with respect to the timing of significant change in behavior, as well as the factors influencing this change. Overall it can provide an important piece of information regarding the preventive measures in a major subset of the population at risk of alcohol-use disorders and utilizing them at a time when the prevention can have a maximal impact.
\end{abstract}

Keywords: Alcohol; Behaviors; Brain; Drink; Injury; Trauma behavior

\section{Introduction}

Traumatic brain injury (TBI) is one of the leading causes of death or permanent disability worldwide. According to a report from the Centers for Disease Control and Prevention (CDC) in March 2010 [1], an estimated 1.7 million individuals sustain a TBI annually. Reportedly, these injuries are highest for adults aged 20 to 24 years. The leading cause of TBI-related death is due to motor vehicle-traffic injuries, accounting for $50 \%$ of TBIs worldwide [2].

Over the past two decades, approximately 40 percent of all motor vehicle fatalities occurred in crashes in which a driver or non-occupant consumed a measurable level of alcohol prior to the crash, and of these cases, $86 \%$ reported a level of consumption which met the current legal definition for intoxication or impairment. Other causes of TBI that could have an involvement with alcohol are falls and assault.

Even in cases with individuals who are not intoxicated at the time of TBI, a history of an alcohol-use disorder is positive as compared to their peers [3]. When TBI occurs in individuals who have a history of chronic alcohol consumption, it could increase the likelihood of these patients to relapse into alcohol abuse after the injury. In fact, alcohol abuse/dependence is second only to major depressive disorder as a common Axis I psychiatric disorder diagnosed following TBI $[4,5]$.

Alcohol use following TBI is associated with reduced efficacy of rehabilitative measures; increased chances of seizures, behavioral disorders and cognitive dysfunction [6]. An incidence of TBI under the influence of alcohol remains an important predictor of recurrent TBI in the future due to the continuation of alcohol abuse in these patients $[7,8]$. Thus, prevention and treatment of alcohol abuse disorders is an important factor in influencing the eventual prognosis and quality of life in these patients, benefitting long-term health. Currently, there is a growing interest in the pattern of alcohol use in post-injury TBI patients, which can influence decisions involving preventive and treatment strategies, as well as determining the target period to implement these strategies.

In this review, we have further analyzed studies focusing on alcohol use after TBI. Our aim is to summarize the pattern of alcohol use after TBI and its application for an integrated management approach in these patients.

\section{Literature Review}

\section{Patterns of change in alcohol consumption following TBI}

There have been several studies focusing on changes in alcoholrelated behaviors following TBI, however, there is a lack of consensus on the results derived from them. The reason may be multifactorial, including the different time points considered in the studies, the different parameters for comparison with post-injury alcohol use and a number of confounding factors involved, such as the severity of TBI and other co-existing injuries or disorders reported in the patients. 
Most of the studies derive their conclusions on the basis of selfreporting by the patients in a clinical setting. It has been observed that patients with a history of substance abuse generally provide valid and reliable information about their abuse in a clinical setting when they are alcohol-and drug-free and when given assurances of confidentiality $[9,10]$. We will discuss the findings of various studies by comparison of alcohol use in the following groups: i) post-TBI patients vs. non-TBI patients ii) pre-injury with post-injury, iii) post injury at different time intervals following TBI, iv) post-injury in patients with TBI and other injuries and $v$ ) across multiple age groups affected by TBI.

\section{Comparison of post-TBI alcohol use with alcohol use in the non-injured general population}

An important step to study the influence of TBI on alcohol use in affected patients will certainly be to follow up the patients with a history of TBI and compare their alcohol use with the general population who do not suffer from TBI. Accordingly, Kreutzer $[3,11]$ observed that in post-TBI patients, the number of abstinent drinkers was two thirds of the total sample as against to one third in the general population, while the number of moderate to heavy drinkers was comparable across both groups.

Thus, they challenged the earlier observation that TBI increased alcohol consumption. Pagulayan in 2016 [12] observed that while preinjury alcohol use, in terms of the mean number of drinks per week, was higher in TBI patients, alcohol use at 1 month post-injury was lower than in the general population. However, after 6 months there was no difference in alcohol use between the two populations.

Extending these observations to animal models, a comparison between a group of mice subjected to non-contusive closed head TBI and sham controls was made by Lowing [13] to note that alcohol intake from 17 to 24 days was decreased in the TBI mice while sensitivity to alcohol increased. Thus, these studies provide evidence that alcohol use in post-TBI patients is reduced as compared to the general population.

\section{Comparison of preinjury alcohol use with post injury alcohol use}

Most of the studies focusing on alcohol use after TBI compare the change in post-injury alcohol-related behavior against pre-injury use of alcohol and show a significant decline in post-injury alcohol use as compared to pre-injury levels during the first year of injury. Kruetzer $[3,14]$ were among the first to show a decrease in post injury alcohol use as compared to the pre-injury levels. Several additional studies also support the finding that alcohol use significantly decreased during the first year following TBI by Horner [15], Kalakowsky-Hayner [16], Dikmen [17], Bombardier [18].

In addition, these studies reported an increase in the percentage of those abstinent from alcohol, along with a decrease in the rate of heavy alcohol use post-TBI. Ponsford et al. [19] monitored alcohol use of TBI patients for 3 years following injury and found that although the percentage of patients who drank hazardous levels decreased, the frequency of drinking increased. Pagulayan and colleagues followed the drinking pattern over 3 to 5 years and found that majority of participants reported abstinence even at 3 to 5 years which was much higher than pre-injury levels [12].

Also, the rates of heavy alcohol use in patients was reported to be less post-injury as compared to pre-injury levels. However, an animal study which utilized an experimental brain injury model, found an increase in alcohol intake lasting up to 19 days post-injury, which was associated with marked neuroinflammation at the site of injury [20]. In summary, these studies suggest that the initial phase of acute neuroinflammation caused by TBI and exaggerated by previous alcohol use, may be responsible for a transient increase in alcohol intake post-injury, which is reduced by 1 month and remains low until 3 years' post-TBI (Table 1 ).

\begin{tabular}{|c|c|c|c|}
\hline $\begin{array}{l}\text { Reference } \\
\text { s }\end{array}$ & $\begin{array}{l}\text { Study } \\
\text { subjects }\end{array}$ & $\begin{array}{l}\text { Change in alcohol } \\
\text { intake post-TBI as } \\
\text { compared to pre-TBI }\end{array}$ & $\begin{array}{l}\text { Change in alcohol } \\
\text { intake at different } \\
\text { time intervals post- } \\
\text { TBI }\end{array}$ \\
\hline $\begin{array}{l}\text { Kruetzer } \\
\text { and } \\
\text { Wehman } \\
{[1]}\end{array}$ & $\begin{array}{l}\text { Patients with } \\
\text { a history of } \\
\text { TBI referred } \\
\text { to a } \\
\text { university } \\
\text { based } \\
\text { employment } \\
\text { program }\end{array}$ & $\begin{array}{l}\text { Decrease in alcohol } \\
\text { intake post-TBI } \\
\text { (Abstinent population } \\
\text { increased from } 20 \% \text { to } \\
51 \% \text { in subjects moderate } \\
\text { drinkers decreased from } \\
30 \% \text { to } 19 \% \text { heavy } \\
\text { drinkers decreased from } \\
38 \% \text { to } 13 \% \text { ) }\end{array}$ & -- \\
\hline $\begin{array}{l}\text { Kreutzer et } \\
\text { al. [2] }\end{array}$ & $\begin{array}{l}\text { Patients } \\
\text { between } \\
16-20 \text { years } \\
\text { old with a } \\
\text { history of } \\
\text { TBI }\end{array}$ & $\begin{array}{l}\text { Decrease in alcohol } \\
\text { intake at } 8 \text { months post- } \\
\text { TBI (Abstinent population } \\
\text { increased from } 27 \% \text { to } \\
58 \% \text {. Moderate drinkers } \\
\text { decreased from } 37 \% \text { to } \\
18 \% \text {. Heavy drinkers } \\
\text { decreased from } 14 \% \text { to } \\
7 \% \text { ) }\end{array}$ & $\begin{array}{l}\text { Increase alcohol intake } \\
\text { from } 8 \text { months to } 28 \\
\text { months (Abstinent } \\
\text { population decreased } \\
\text { from } 72 \% \text { to } 49 \% \text {. } \\
\text { Moderate-heavy } \\
\text { drinkers increased } \\
\text { from } 25 \% \text { to } 35 \% \text { ) }\end{array}$ \\
\hline $\begin{array}{l}\text { Horner et } \\
\text { al. [3] }\end{array}$ & $\begin{array}{l}\text { Adult } \\
\text { patients with } \\
\text { history of } \\
\text { TBI } \\
\text { interviewed } \\
\text { telephonicall } \\
\text { y }\end{array}$ & $\begin{array}{l}\text { Decrease in alcohol } \\
\text { intake at 1-year post-TBI } \\
\text { ( } 49 \% \text { of Heavy drinkers, } \\
\text { and } 48 \% \text { of moderate } \\
\text { drinkers reported } \\
\text { decrease in drinking) }\end{array}$ & -- \\
\hline $\begin{array}{l}\text { Kolakowsk } \\
\text { y-Hayner et } \\
\text { al. [4] }\end{array}$ & $\begin{array}{l}30 \text { Model } \\
\text { Systems TBI } \\
\text { patients that } \\
\text { returned for } \\
1 \text { year follow } \\
\text { up after TBI }\end{array}$ & $\begin{array}{l}\text { Decrease in alcohol } \\
\text { intake at 1-year post-TBI } \\
(40 \% \text { of heavy drinkers } \\
\text { and } 29 \% \text { of moderate } \\
\text { drinkers were abstinent. } \\
\text { Moderate drinkers } \\
\text { decreased to } 62.5 \% \text { of } \\
\text { pre-injury levels, Heavy } \\
\text { drinkers decreased to } \\
29.4 \% \text { of pre-injury } \\
\text { levels) }\end{array}$ & -- \\
\hline $\begin{array}{l}\text { Bombardier } \\
\text { et al. [5] }\end{array}$ & $\begin{array}{l}\text { Patients } \\
\text { admitted } \\
\text { with TBI } \\
\text { followed } \\
\text { over } 1 \text { year }\end{array}$ & $\begin{array}{l}\text { Decrease in alcohol } \\
\text { intake at 1-year post-TBI } \\
\text { (Abstinent population } \\
\text { increased from 24 } \\
\text { patients to } 62 \text { patients. } \\
\text { Heavy } 4 \text { drinkers } \\
\text { decreased from } 71 \\
\text { patients to 29 patients) }\end{array}$ & -- \\
\hline $\begin{array}{l}\text { Dikmen et } \\
\text { al. [6] }\end{array}$ & $\begin{array}{l}\text { Hospitalized } \\
\text { head injury } \\
\text { patients }\end{array}$ & $\begin{array}{l}\text { Decrease in alcohol } \\
\text { intake at 1-month post- } \\
\text { TBI }\end{array}$ & $\begin{array}{l}\text { Increase in alcohol } \\
\text { intake from } 1 \text { month to } \\
\text { 1-year post-TBI }\end{array}$ \\
\hline $\begin{array}{l}\text { Ponsford et } \\
\text { al. [7] }\end{array}$ & $\begin{array}{l}\text { Inpatients } \\
\text { with TBI } \\
\text { who } \\
\text { completed } \\
\text { Alcohol use } \\
\text { disorders } \\
\text { test }\end{array}$ & $\begin{array}{l}\text { Decrease in alcohol } \\
\text { intake at 1-year post-TBI } \\
\text { (Abstinent population } \\
\text { increased from } 8.4 \% \text { to } \\
30 \% \text {. Patients drinking } 2 \\
\text { to } 3 \text { times/wk decreased } \\
\text { from } 23.5 \% \text { to } 15.8 \% \text {, }\end{array}$ & $\begin{array}{l}\text { Increase in alcohol } \\
\text { intake from } 1 \text { year to } 2 \\
\text { years (Abstinent } \\
\text { population decreased } \\
\text { from } 30 \% \text { at } 1 \text { year to } \\
21.4 \% \text { at } 2 \text { years post- } \\
\text { TBI. Patients drinking }\end{array}$ \\
\hline
\end{tabular}




\begin{tabular}{|c|c|c|c|}
\hline & & $\begin{array}{l}\text { and drinking }>4 \text { times } / \mathrm{wk} \\
\text { decreased from } 13.4 \% \text { to } \\
6.7 \% \text {. Patients drinking } 1 \\
\text { to } 2 \text { drinks per session } \\
\text { increased from } 42.1 \% \text { to } \\
47.1 \% \text { while those } \\
\text { drinking } 7 \text { to } 9 \text { drinks and } \\
>10 \text { drinks per session } \\
\text { decreased from } 8.4 \% \text { to } \\
4.6 \% \text { and } 13.1 \% \text { to } 8 \% \\
\text { respectively. }\end{array}$ & $\begin{array}{l}2-3 \text { times/wk increased } \\
\text { from } 15.8 \% \text { to } 21.4 \% \\
\text { and drinking >4 } \\
\text { times/wk increased } \\
\text { from } 6.7 \% \text { to } 11.1 \% \text {, } \\
\text { Patients drinking } 7-9 \\
\text { drinks per session } \\
\text { increased from } 4.6 \% \text { at } \\
1 \text { year to } 8.7 \% \text { at } 2 \\
\text { years post-TBI) }\end{array}$ \\
\hline $\begin{array}{l}\text { Pagulayan } \\
\text { et al. [8] }\end{array}$ & $\begin{array}{l}\text { Adults with a } \\
\text { history of } \\
\text { TBI }\end{array}$ & $\begin{array}{l}\text { Decrease in alcohol } \\
\text { intake at 1-month post- } \\
\text { TBI (Abstinent population } \\
\text { increased from } 38 \% \text { pre- } \\
\text { TBI to } 88 \% \text { at } 1 \text {-month } \\
\text { post-TBI, Drinks per week } \\
\text { decreased from } 12.2 \text { pre- } \\
\text { TBI to } 0.9 \text { at } 1 \text { month } \\
\text { post-TBI) }\end{array}$ & $\begin{array}{l}\text { Increase in alcohol } \\
\text { intake from } 1 \text { month } \\
\text { through } 6 \text { months, } 1 \\
\text { year and } 3 \text { to } 5 \text { years. } \\
\text { (Abstinence decreased } \\
\text { from } 88 \% \text { at } 1 \text {-month } \\
\text { post-TBI to } 67 \%, 61 \% \\
\text { and } 38 \% \text { at } 6 \text { months, } \\
1 \text { year and } 3 \text { to } 5 \text { years } \\
\text { respectively. } \\
\text { Drinks per session } \\
\text { increased from } 0.9 \text { at } \\
1 \text {-month post-TBI to } \\
3.4,4.0 \text { and } 4.3 \text { at } 6 \\
\text { months, } 1 \text { year and } 3 \\
\text { to } 5 \text { years respectively) }\end{array}$ \\
\hline
\end{tabular}

Table 1: Comparing pre-TBI and post-TBI alcohol intake.

\section{Comparison of post injury alcohol use at different time intervals after TBI}

As most studies observed a decrease in alcohol use post-TBI, there is a growing interest in how alcohol intake differs at various time intervals during the post-injury period. Dikmen [17] followed patients with acute head injury for up to four years and reported that the frequency of drinking and the number of drinks consumed per sitting increased from 1 month to 1 year after TBI but never reached the preinjury values.

Kruetzer [14] reported an increase in alcohol intake at 8 and 28 months post-injury, with abstinence rates decreasing and percentage of moderate-heavy drinkers increasing in a population of young adults. A follow-up study by Kruetzer et al. saw a similar finding during a prospective multicenter analysis of alcohol-use to conclude that drinking was increased from 1 through 3 years post-TBI and number of abstainers decreased [11]. Again, the levels of post-injury alcohol intake always remained lower as compared to pre-injury levels. Ponsford [19] observed that the proportion of patients drinking at hazardous levels and alcohol dependence increased from 1 year to 2 years post-TBI. The frequency of drinking increased 2 years postinjury as compared to 1 year, with patients drinking 2-3 times or even more than 4 times a week (Table 1 ).

A more detailed work done recently by Pagulayan and colleagues [12] showed that the decrease in alcohol intake was maximum at 1 month post-injury and then rose gradually through 6 months, 1 year and 3 to 5 years time points. The percentage of patients consuming moderate to heavy alcohol as also the number of drinks consumed per week by patients increased significantly from 1 month to 6 months but not after that. This also means the largest proportion of patients returned to drinking between 1 to 6 months and hence this should be the target period for the intervention to prevent alcohol dependence in these patients. In summary, the initial decrease in alcohol drinking that was observed during an acute post injury period, increased subsequently during the follow-up. The maximum decrease was observed as early as 1 month following TBI with a gradual increase over 6 months up to 3 to 5 years. However, as mentioned earlier the levels never reached the pre-injury baseline values. No studies were conducted beyond this time point.

\section{Comparison of post-injury alcohol use in patients with TBI and in patients with other injuries}

Kreutzer [3] in 1990 observed that in patients with TBI referred for supportive employment services when compared with a sample of 3000 persons with disabilities other than TBI, the TBI group had more abstainers and less drinkers in each group of drinkers (infrequent, light, moderate and heavy).

Kruetzer [3] showed that the alcohol use was lower and abstinence was higher in TBI patients post-injury as compared to patients with other neurological injuries including Spinal cord injury(SCI) and neuromuscular diseases. Kalakowsky [16] when comparing the alcohol behavior in patients with TBI and spinal cord injury, observed a higher frequency of alcohol (daily drinking) use in patients with SCI as compared to TBI ( 2 to 3 times per week) post-injury. Thus, these studies suggest there is a decrease in alcohol use after TBI as compared to patients with other injuries.

\section{Comparison of alcohol use across different age groups affected by TBI}

Although alcohol intake is reported to decrease after TBI in the adult population, the results are reverse in children and adolescents, especially when followed over a longer course of time. Many studies correlate childhood TBI with an increased risk of alcohol abuse in adulthood. Whether it should be a result of the effects of TBI on a developing brain or just a finding of a long-term follow-up that can be available with this age group is yet to be discovered. Weil in 2016 [21] found that mice injured as juveniles had greater alcohol selfadministration in adulthood as compared to those injured as adults.

They stated that early injuries increase the rewarding properties of alcohol. Corrigan in 2013 [22] studied population up to 20 years after TBI in a retrospective analysis and observed that the proportion of substance abuse including alcohol was higher in patients who had experienced TBI before the age of 16 years. Ilie [23] compared students of 9th to 12th grade and observed that the adjusted odds of past year drinking and binge drinking increased by a factor of 2 for students with a history of TBI compared to the non-injured students.

Kruetzer and colleagues [14] observed that in patients 16 to 20 years of age with a history of TBI showed a decrease in alcohol use acutely at 8 months post-TBI but this phenomenon was followed by an increase to pre-injury levels around 2 years. As against this, alcohol use never reached the pre-injury levels in adults as seen in majority of studies above. Children generally do not have a history of alcohol abuse and are not positive for blood alcohol levels that are generally used as parameters to compare the change in alcohol behavior. Hence, these findings require a further exploration in this direction.

Among the adult population who show a decrease in alcohol intake after TBI, patients aged 21 to 30 years showed a greater reduction in the frequency of alcohol intake than 15 to 20 years in one study (3.1 to 1.4 and 1.5 to 1.0 respectively)[17] and similarly, patients less than 25 years returned to drinking at higher levels more than those between 25 to 34 years in another study group [19]. These findings again point 
towards a difference in the alcohol behavior across age groups with a trend towards increased alcohol preference for patients with TBI at a younger age. Whether the reason for this discrepancy is the lack of follow-up in the adult population over a long period of time or a different mechanism underlying the use of alcohol and TBI in a pediatric age group remains unknown and requires more in-depth studies.

\section{Factors Influencing the Patterns in Alcohol Consumption}

\section{Patient characteristics}

A study by Reslan [24] showed that age at the time of TBI, education and task oriented coping style post injury were all statistically significant in determining the nature of alcohol use post TBI. In general, males have a higher rate of alcohol use disorders compared to females $[25,26]$. The potential cause for this difference is cited as a lower genetic risk for AUDs and a tendency for females to suffer more negative biological consequences from drinking as compared with males. Additionally, certain psychosocial factors in males may increase their risk for alcohol use disorders [27].

However, there are discrepancies regarding the gender differences in alcohol preference post TBI as is seen in the related studies. While the majority of studies show a similar increased preference for alcohol by males as compared to females $[12,15,19]$, others show no significant difference between the sexes [14]. In a study by Weil [21], the juvenile mice that were subjected to brain injury showed an increase in alcohol consumption following the injury which was limited to female mice only. Using a gene expression analysis, they saw that alcohol administration alters the rewarding state in several brain regions of juvenile mice including though not limited to the nucleus accumbens, amygdala and periaqueductal gray, but only in females. Thus, further studies are warranted in this area for a better conclusion.

There is a highly predictive co-relation between drinking before injury and drinking after injury $[14,18,19]$. This means a history of alcohol abuse prior to TBI increases the likelihood of alcohol abuse disorders and hazardous drinking post-TBI. A history of depression and presence of post-traumatic stress disorder has also been linked to heavy drinking though there is no direct evidence to prove this [6]. Among the reasons thought to be responsible specifically for the decrease in alcohol use post-TBI are the lack of access to alcohol while in the healthcare facility, physical injuries caused by the TBI and advice by the health care providers [28]. Patients who received treatment for alcohol abuse after TBI decreased the amount they drank per sitting more than those who did not receive the treatment[17].

\section{Injury characteristics}

The injury severity determined by time to follow commands and time since injury are cited as factors influencing the change in alcohol behavior after TBI [24]. According to Pagulayan [12], though there was a trend of more number of abstinent patients in the group of severe TBI, the differences were not significant. Additional studies did not report a significant relationship between TBI severity and change in alcohol behavior as well $[11,15,16]$. However, a study by Dikmen [17] reported that patients with severe head injuries decreased their alcohol intake more than those with milder injuries. For example, patients with GCS 12 or lower decreased their frequency of drinking from an average of thrice per week to once per week, 1 year after the injury.
Miller [29] studied change in alcohol behavior only in mild TBI patients and saw an increase in alcohol dependence in first 30 days following mild TBI with a gradual decrease up to and beyond 6 months. Though this may be related to the acute inflammatory changes following TBI [20], Miller suggested that mild TBI may be differentiated from moderate to severe TBI in terms of timing of the risk of addition disorders. These findings suggest that though severity of TBI may not have a proven significant influence on the use of alcohol post-injury, further studies are necessary to arrive at a conclusion.

\section{Mechanisms behind Change in Alcohol-Related Behavior Following TBI}

The decrease in alcohol intake seen during the acute post-TBI period may be explained to a certain extent by the factors mentioned above. However, certain pathophysiological mechanisms occurring after TBI may concurrently play an important role in determining alcohol-related behaviors.

\section{Neuropsychological mechanisms}

TBI can influence the motivational equation behaviors regulated by the brain by increasing negative mood, anxiety, reducing social cohesion and impairing the ability to process the potential negative consequences of excessive drinking [30,31]. This may cause the patients to return to alcohol drinking after the injury.

\section{Ischemic injury to brain regions}

The injury to various brain areas due to the impact of TBI can be a reason for change in substance use disorders after TBI. Though there is lack of evidence for this specifically in context to alcohol, a study by Naqvi et al. in 2007 [32] found that persons with injuries to the insula were more likely to undergo a disruption of smoking addiction in terms of their ability to quit smoking easily, immediately and without relapse and showed less intense craving during abstinence.

Working on similar lines in experimental animals, pharmacological lesion of the nucleus accumbens [33] and amygdala [34] as well as electrolytic lesions of the amygdala [35] resulted in decreased ethanol consumption. On the other hand, lesions of the lateral habenula [36] and Rostromedial Tegmental nucleus (RMTg) [37] have been shown to result in increased ethanol consumption in animal models. This opens a new direction for a suggestive underlying mechanism of change in alcohol behavior following brain injury to different brain regions.

\section{Dopaminergic dysfunction and reductions in DARPP-32 phosphorylation}

TBI is associated with an initial increase in dopamine followed by an extended period of striatocortical hypodopaminergic state. Dopamine dysfunction is associated with a risk of alcohol-use disorders. Though this doesn't explain the decrease in alcohol intake observed clinically, it is important from the point of view of increased risk of alcohol abuse that is seen in TBI patients and hence, the need for intervention to prevent it. Conversely, DARPP-32 is a downstream mediator of dopamine D1 receptor.

Reductions in DARPP-32 phosphorylated (active) state is associated with reduced motivation for drinking and concurrent increased sensitivity to alcohol. Reduction in DARPP-32 phosphorylation has 
Page 5 of 7

been reported after experimental brain injury in rats and thus may be the reason for reduced drinking in TBI subjects. Weil et al. observed that TBI may decrease Brain derived neurotrophic factor (BDNF) expression and this is associated with a dopaminergic dysfunction putting these patients at risk for alcohol abuse $[21,38]$.

\section{Neural inflammation}

TBI is associated with neural inflammation and a chronic alcohol use can increase the inflammation in such patients. Inflammation is also seen to increase the incidence of alcohol abuse disorder [6]. Also, it may be responsible for acute increase in alcohol intake in the initial few days following TBI as observed by Mayeux [20].

\section{Clinical Implications of the Change in Alcohol Behavior after TBI}

Alcohol use disorders are an important determinant of rehabilitation success following TBI. Alcohol can impair cognitive and neurological function after TBI, which can influence the recovery. Furthermore, the determination of alcohol-related behavioral patterns after TBI is important in deciding the time to target the interventional measures. The success of alcohol prevention strategies will depend on the mindset of patients to undergo a change in their alcohol habits.

\section{Assessing the severity of the problem}

According to Dikmen [17], the blood alcohol levels in the emergency department at the time of presentation are indicative of a history of problem drinking and should serve as a reference for deciding the nature of intervention in the initial weeks after TBI when the probability of drinking is less among the patients.

Assessing the problem immediately post-injury when the alcohol preference among the patients is low will underestimate the problem likely to be experienced late after the injury. Bombardier [39] in their study suggested that soon after TBI, drinkers show increased readiness to change their alcohol intake. A history of chronic alcohol problems, alcohol involvement at the time of injury and greater recent alcohol consumption are associated with greater contemplation of the possibility that one needs to change his or her alcohol use. Also important is that since the incidence of post-injury abuse is proportional to pre-injury alcohol use, patients with a history of alcohol abuse might require additional interventions and longer follow-up [15].

\section{Time for intervention}

Specifying time frames is an important part of the assessment of alcohol-use disorders. Most of the studies hint towards the maximum decrease in alcohol intake at 1-month post-injury and increase gradually up to 1 year after the injury and then remain almost stable. Thus, the period of maximum relapses occurs during the first year after TBI and hence this time must be considered critical for conducting secondary prevention programs. Pagulayan et al. suggested a further contraction in this period when they observed maximum relapses between 1 month to 6 months making it the best period for prevention programs. Future studies showing the results of interventions to decrease alcohol dependence during the initial 6 months post-injury can be done to provide a significant approach to curtail this problem.

\section{Co-existing problems}

Horner et al. also stress at the importance of assessing depression in these patients as depression is a determinant of alcohol use. These patients are at risk of PTSD which may influence their alcohol intake.

\section{Discussion}

\section{Key considerations for intervention and management strategies targeting patients at risk of alcohol abuse after TBI}

Motivation: At risk persons must be educated and motivated to abstain and learn coping strategies starting from the initial weeks postinjury as a part of routine care while admitted in the hospital. In the post-acute period at risk patients could be referred for relapse prevention strategies and booster sessions for motivation to remain abstinent. Drinking behavior must be monitored during follow-up visits to identify relapse at the earliest $[18,40,41]$.

Social support: Social support must be extended by the attending physicians, hospital staff and family members to help abstain from drinking during the initial weeks when the risk of relapse is higher. Family members can be educated to identify the signs of relapse and use relapse prevention strategies to prepare survivors for this situation. Interested persons can also be referred to alcoholics anonymous who encourage survivors to take responsibility of their behavior.

Combined brain injury and substance abuse treatment programs: Brain injury rehabilitation professionals often lack expertise in alcohol abuse treatment. Hence an integrated approach for TBI patients who are at risk of alcohol abuse must be considered with health professionals who are experts in both the treatment strategies on an inpatient or outpatient basis. A group psychotherapy model based on this principle was used by Delmonico, Hanley-Peterson, and Englander in 1998 [42] and showed treatment success in terms of reduced clinic visits, fewer emergency calls for substance abuse-related health problems, and increased stability in housing and relationships. Sander [43] used a brief intervention session in patients of TBI after they recovered from the post traumatic amnesia using a 10-minute educational DVD that described potential adverse effects of alcohol and drug use after TBI and encouraged patients to carefully consider the pros and cons of substance use. This was followed by a brief motivational interview to talk about potential benefits of change. They found the intervention effective in severe injury patients who attributed the injury to alcohol and this may increase the readiness to change in some settings. This shows the effectiveness of incorporation of a discussion of relationship between alcohol and injury in changing future alcohol preference.

Environmental enrichment : In their experimental study, Weil [21] used environmental enrichment as a manipulation that modulates addiction related behaviors and protects the nervous system from TBIinduced damage and normalize dopaminergic tone. They concluded that environmental enrichment reduced axonal degeneration, normalized BDNF gene expression and abolished the enhancement of drinking behavior in juvenile rats. Similar interventions are worth trying in patients of TBI.

\section{Conclusion}

Traumatic brain injury is a major burden to the medical and economic sector of the society. Patients of Traumatic Brain injury have a strong history of alcohol addiction and hence remain at risk for 
relapse during the post-injury period. The intake of alcohol is seen to be low during the acute post-injury period and rises gradually during the first year following injury, but does not reach the pre-injury levels for at least a couple of years. The most effective period for interventions to prevent relapse into alcohol use is seen to be the initial six months following TBI.

During this period patients also show willingness to change their alcohol-related behaviors and hence must be given an integrated and targeted approach towards preventive measures. An involvement of physicians and family members is equally important in making a positive change during this period in preventing the relapse. However, future studies must focus on a long term follow up in these patients to determine the alcohol behavior with and without preventive interventions especially since children who are injured earlier in life show an increased incidence of alcohol use disorders when followed until adulthood.

Also, more detailed knowledge of the reasons underlying the initial decrease in alcohol intake must be determined to help in keeping the patients in remission. There is also a need to focus on the reason for few patients to relapse earlier as compared to others. In summary, research aimed at a greater understanding of post-injury alcohol use in TBI patients by applying the present available knowledge can help reduce the burden of alcohol abuse in TBI patients.

\section{References}

1. Faul M (2010) Traumatic brain injury in the United States : Emergency department visits, hospitalizations, and deaths, 2002-2006. National Center for injury and control. Atlanta Ga: USA. Department of Health and Human Services, Centers for Disease Control and Prevention, National Center for Injury Prevention and Control.

2. Edward Brodd GC, Date E (2004) Traumatic brain injury independent study course, USA. Department of Veterans. Washington DC: Department of Veterans Affairs, Employee Education System.

3. Kreutzer JS, Wehman PH, Harris JA, Burns CT, Young HF (1991) Substance abuse and crime patterns among persons with traumatic brain injury referred for supported employment. Brain Inj 5: 177-187.

4. Hibbard MR, Uysal S, Kepler K, Bogdany J, Silver J (1998) Axis I psychopathology in individuals with traumatic brain injury. J Head Trauma Rehabil 13: 24-39.

5. Koponen S, Taiminen T, Portin R, Himanen L, Isoniemi H, et al. (2002) Axis I and II psychiatric disorders after traumatic brain injury: A 30-year follow-up study. Am J Psychiatry 159: 1315-1321.

6. Weil ZM, Corrigan JD, Karelina K (2016) Alcohol abuse after traumatic brain injury: Experimental and clinical evidence. Neurosci Biobehav Rev 62: 89-99.

7. Vaaramo K, Puljula J, Tetri S, Juvela S, Hillbom M (2014) Head trauma sustained under the influence of alcohol is a predictor for future traumatic brain injury: A long-term follow-up study. Eur J Neurol 21: 293-298.

8. Winqvist S, Luukinen H, Jokelainen J, Lehtilahti M, Näyhä S, et al. (2008) Recurrent traumatic brain injury is predicted by the index injury occurring under the influence of alcohol. Brain Inj 22: 780-785.

9. Babor TF, Stephens RS, Marlatt GA (1987) Verbal report methods in clinical research on alcoholism: response bias and its minimization. J Stud Alcohol 48: 410-424.

10. Doyle SR, Donovan DM (2009) A validation study of the alcohol dependence scale. J Stud Alcohol Drugs 70: 689-699.

11. Kreutzer J, Wltol AD, Sander A, Cifn DX, Martvitz JH, et al. (1996) A prospective longitudinal multicenter analysis of alcohol use patterns among persons with traumatic brain injury. J Head Trauma Rehabil 11: 58-69.
12. Pagulayan KF, Temkin NR, Machamer JE, Dikmen SS (2016) Patterns of alcohol use after traumatic brain injury. J Neurotrauma 33: 1390-1396.

13. Lowing JL, Susick LL, Caruso JP, Provenzano AM, Raghupathi R, et al. (2014) Experimental traumatic brain injury alters ethanol consumption and sensitivity. J Neurotrauma 31: 1700-1710.

14. Kreutzer JS, Witol AD, Marwitz JH (1996) Alcohol and drug use among young persons with traumatic brain injury. J Learn Disabil 29: 643-651.

15. Horner MD, Ferguson PL, Selassie AW, Labbate LA, Kniele K, et al. (2005) Patterns of alcohol use 1 year after traumatic brain injury: A population-based, epidemiological study. J Int Neuropsychol Soc 11: 322-330.

16. Kolakowsky-Hayner SA, Gourley EV 3rd, Kreutzer JS, Marwitz JH, Meade MA, et al. (2002) Post-injury substance abuse among persons with brain injury and persons with spinal cord injury. Brain Inj 16: 583-592.

17. Dikmen SS, Machamer JE, Donovan DM, Winn HR, Temkin NR (1995) Alcohol use before and after traumatic head injury. Ann Emerg Med 26: 167-176.

18. Bombardier CH, Temkin NR, Machamer J, Dikmen SS (2003) The natural history of drinking and alcohol-related problems after traumatic brain injury. Arch Phys Med Rehabil 84: 185-191.

19. Ponsford J, Whelan-Goodinson R, Bahar-Fuchs A (2007) Alcohol and drug use following traumatic brain injury: A prospective study. Brain Inj 21: 1385-1392.

20. Mayeux JP, Teng SX, Katz PS, Gilpin NW, Molina PE (2015) Traumatic brain injury induces neuroinflammation and neuronal degeneration that is associated with escalated alcohol self-administration in rats. Behav Brain Res 279: 22-30.

21. Weil ZM, Karelina K, Gaier KR, Corrigan TE, Corrigan JD (2016) Juvenile traumatic brain injury increases alcohol consumption and reward in female mice. J Neurotrauma 33: 895-903.

22. Corrigan JD, Bogner J, Mellick D, Bushnik T, Dams-O'Connor K, et al. (2013) Prior history of traumatic brain injury among persons in the traumatic brain injury model systems national database. Arch Phys Med Rehabil 94: 1940-1950.

23. Ilie G, Mann RE, Hamilton H, Adlaf EM, Boak A, et al. (2015) Substance use and related harms among adolescents with and without traumatic brain injury. J Head Trauma Rehabil 30: 293-301.

24. Reslan S, Hanks RA (2014) Factors associated with alcohol-related problems following moderate to severe traumatic brain injury. Rehabil Psychol 59: 453-458.

25. Ely M, Hardy R, Longford NT, Wadsworth ME (1999) Gender differences in the relationship between alcohol consumption and drink problems are largely accounted for by body water. Alcohol Alcohol 34: 894-902.

26. Erol A, Karpyak VM (2015) Sex and gender-related differences in alcohol use and its consequences: Contemporary knowledge and future research considerations. Drug Alcohol Depend 156: 1-13.

27. Nolen-Hoeksema S, Hilt L (2006) Possible contributors to the gender differences in alcohol use and problems. J Gen Psychol 133: 357-374.

28. Oddy M, Tyerman A, Jenkins D (1985) Social adjustment after closed head injury: A further follow-up seven years after injury. J Neurol Neurosurg Psychiatry 48: 564-568.

29. Miller SC, Baktash SH, Webb TS, Whitehead CR, Maynard C, et al. (2013) Risk for addiction-related disorders following mild traumatic brain injury in a large cohort of active-duty U.S. airmen. Am J Psychiatry 170: 383-390.

30. Bjork JM, Grant SJ (2009) Does traumatic brain injury increase risk for substance abuse? J Neurotrauma 26: 1077-1082.

31. Osborn AJ, Mathias JL, Fairweather-Schmidt AK (2014) Depression following adult, non-penetrating traumatic brain injury: A meta-analysis examining methodological variables and sample characteristics. Neurosci Biobehav Rev 47: 1-15.

32. Naqvi NH, Rudrauf D, Damasio H, Bechara A (2007) Damage to the insula disrupts addiction to cigarette smoking. Science 315: 531-534.

33. Wilden JA, Qing KY, Hauser SR, McBride WJ, Irazoqui PP, et al. (2014) Reduced ethanol consumption by alcohol-preferring (P) rats following 
Citation: Shiwalkar N, Gregor D, Fu R, Bekke A, Ye J (2017) Changes in Alcohol-Related Behavior Following an Incident of Traumatic Brain Injury. J Trauma Treat 6: 392. doi:10.4172/2167-1222.1000392

Page 7 of 7

pharmacological silencing and deep brain stimulation of the nucleus accumbens shell. J Neurosurg 120: 997-1005.

34. Möller C, Wiklund L, Sommer W, Thorsell A, Heilig M (1997) Decreased experimental anxiety and voluntary ethanol consumption in rats following central but not basolateral amygdala lesions. Brain Res 760 : 94-101.

35. Dhaher R, Finn DA, Oberbeck DL, Yoneyama N, Snelling CC, et al. (2009) Electrolytic lesions of the medial nucleus accumbens shell selectively decrease ethanol consumption without altering preference in a limited access procedure in C57BL/6J mice. Pharmacol Biochem Behav 92: 335-342.

36. Haack AK, Sheth C, Schwager AL, Sinclair MS, Tandon S, et al. (2014) Lesions of the lateral habenula increase voluntary ethanol consumption and operant self-administration, block yohimbine-induced reinstatement of ethanol seeking, and attenuate ethanol-induced conditioned taste aversion. PLoS One 9: e92701.

37. Fu R, Chen X, Zuo W, Li J, Kang S, et al. (2016) Ablation of mu opioid receptor-expressing GABA neurons in rostromedial tegmental nucleus increases ethanol consumption and regulates ethanol-related behaviors. Neuropharmacology 107: 58-67.
38. Bales JW, Yan HQ, Ma X, Li Y, Samarasinghe R, et al. (2011) The dopamine and cAMP regulated phosphoprotein, $32 \mathrm{kDa}$ (DARPP-32) signaling pathway: A novel therapeutic target in traumatic brain injury. Exp Neurol 229: 300-307.

39. Bombardier CH, Ehde D, Kilmer J (1997) Readiness to change alcohol drinking habits after traumatic brain injury. Arch Phys Med Rehabil 78: $592-596$.

40. Langley MJ, Lindsay WP, Lam CS, Priddy DA (1990) A comprehensive alcohol abuse treatment programme for persons with traumatic brain injury. Brain injury 4: 77-86.

41. Taylor LA, Kreutzer JS, Demm SR, Meade MA (2003) Traumatic brain injury and substance abuse: A review and analysis of the literature. Neuropsychological Neuropsychol Rehabil 13: 165-188.

42. Delmonico RL, Hanley-Peterson P, Englander J (1998) Group psychotherapy for persons with traumatic brain injury: Management of frustration and substance abuse. J Head Trauma Rehabil 13: 10-22.

43. Sander AM, Bogner J, Nick TG, Clark AN, Corrigan JD, et al. (2012) A randomized controlled trial of brief intervention for problem alcohol use in persons with traumatic brain injury. J Head Trauma Rehabil 27: 319-330. 